\title{
OP-ED1: TOWARDS AN ENABLING ENVIRONMENT FOR A DIGITAL ECOSYSTEM : A FOUNDATION FOR ENTREPRENEURIAL ACTIVITY
}

\author{
Prof Shaun Pather ${ }^{1}$ Orcid ID: https://orcid.org/0000-0002-4667-222X
}

During a recent webinar on the topic of digital inclusion and women entrepreneurship, I had the opportunity to share my perspectives in respect of ICT policy with a very engaged audience from across South Africa.

The event reminded us of the commitment of the University of the Western Cape to create platforms not only for intellectual debate, but with a view to ensure an impact on the communities we serve. This webinar was conceived with the objective that women would benefit from the discourse that would impact their lives as entrepreneurs.

\section{Digital Inequality is not just about infrastructure}

Currently the prevailing situation of digital inequality is a historical one, depicted in both geography (urban versus rural) and income status (wealthy versus poor). The historically entrenched economic and societal disparities have been reflected in the emerging digital society too. From a policy perspective, a key problem is the domination of ICT infrastructure or supply side policies. Key policy decisions, which were made in the post-2000 era following the World Summit on the Information Society (WSIS), resulted in the promulgation of the Electronic Communication Act of 2005. This remains a core piece of legislation that supports a converged telecommunications environment. The focus of this act and many subsequent pieces of policy, was the provisioning of network infrastructure. However, the eradication of digital inequality is beyond that of provisioning ICT infrastructure. Policy needs to enable a digital ecosystem. In this ecosystem interventions must stimulate demand. In addition, there must be programmes which drive awareness, and develop capacity for entrepreneurs to harness and integrate the appropriate digital tools into the fabric of their business operations.

\section{Telecommunications Market failure}

The digital divide that we face today suggests that there is still market failure, despite internet penetration statistics that may seem to suggest success. For example, revenues in this sector increased by 2.4\%, from R194 billion in 2019 to R201 billion in 2020; the national population coverage for 3G increased from $99.7 \%$ in 2019 to $99.8 \%$ in 2020; and smartphone subscriptions increased from 53 million in 2019 to 60 million in 2020. However, market dominance prevails. For example, in the mobile sector just two licensees dominate up to $91 \%$ of the market, which indicates a glaring lack of competition. The consequence thereof is that a high cost to communicate prevails, and a satisfactory level of network provision to enable digital enterprises to thrive is focused only in geographical areas that are deemed to be profitable.

This results in a skewed access to the network, Furthermore, internet penetration at household level is still very low. The network access problem is further exacerbated by the South African gender bias. The statistics reveal that there is a 53.3\% disparity between male- and female-headed households with internet access.

\section{The Problem of Policy Implementation Lethargy}

'Policy implementation lethargy' is the phrase l use to explain the reasons for the relatively slow pace of transformation in relation to the Digital Divide. A good example is this country's process of digital migration which commenced in 2007, and yet today we are still behind many other African countries who have completed their migration processes. It was recently announced by Government that the renewed target date for finalisation is 2023. In effect this has

1University of the Western Cape, Department of Information Systems,

Email spather@uwc.ac.za 
robbed us of the promised Digital Dividend that could have yielded high radio spectrum to enable cost-effective telecommunications deployment, especially in many impoverished communities and hard to reach geographies. Another problem at hand is that of sustained and effective leadership. In South Africa, after the passing of the late Minister Ivy Matsepe-Casaburri in 2008, the Department of Communications has had no less than eleven ministers, taking into account the ill-informed decision to split the Department in 2014. This has resulted in several leadership vacuums in the Department, the consequence of which has been a lack of regulation innovation. As a result we have had a deficit of the firm and effective leadership that was needed to bring about the desperately needed synergy and cooperation between various stakeholders to ensure a digital ecosystem solution to the divide.

Notwithstanding, the good news is that there is a lot of effective research taking place to frame the problem and to develop solutions. Research that we have undertaken indicates that facilitating conditions, in particular the affordability of data, support or guidance to use ICTS and resources (access to reliable networks), are determinants, amongst others, of entrepreneurial intention to use ICT to support business operations. Such findings go a long way to help us to design solutions to address the digital divide.

In addition, a new National Integrated ICT Policy White Paper, gazetted in 2016, paves the way for an integrated ecosystem approach to achieve a functional South African digital society. It will need a dedicated and unencumbered leadership to take charge of the implementation to ensure that this integrated and cohesive policy paper is converted into meaningful programmatic action on the part of government.

\section{How To Build an Enabling Environment for a thriving Digital Ecosystem}

So what does an enabling environment look like if we want to transform this space radically? Based on my research and associated evidence, the Digital Ecosystem is multi-faceted. The ecosystem must be engineered to promote the ability of individuals to harness their agency to realize the outcomes of individual choice to make ICTs an integral part of their daily life. This includes entrepreneurial activity.

It comes down to the key elements of Access to infrastructure and Adoption thereof to enable Social Appropriation of ICTs. The goal is to achieve the social appropriation of ICTs to achieve Effective Use (a phrase coined by my late colleague, Michael Gurstein) thereof.

Policy right now focuses predominantly on how to create access. Instead, what is required is an enabling policy environment that integrates the afore-mentioned elements in such a way that are not solely focus on infrastructure provision. This is one of the causes of policy failure.

There are many sound proposals in the National Integrated ICT Policy White Paper, including that of a digital development fund; the extension of infrastructure; end user equipment subsidies; support for digital literacy programmes; access to digital government services; and creative ways for efficient deployment of radio spectrum to benefit more people.

Most importantly, the White Paper dedicates an entire chapter on industry growth, which outlines support for the innovative use of ICT by SMMEs to improve productivity, sustainability and competitiveness.

\section{Zenzeleni Networks: An example of Innovation to work around policy bottlenecks}

One of UWC's biggest successes in recent years is a rural connectivity project which emanated from a PhD and subsequent post-doctoral research. Today the Zenzeleni Networks Not-for-Profit Company - a UWC spin-off comprising a board of multi-stakeholders from the university, a globally based NGO, the Association of Progressive Communications, Ellipsis Regulatory and a rural community cooperative from a remote Eastern Cape village of Mankosi - is an award-winning exemplar of how affordable access to the internet may be realised to the poorest of the poor communities.

To date the Zenzeleni NPC has established two rural cooperatives which are providers of internet connectivity through low-cost WiFi networks in the Eastern Cape. Success has been demonstrated despite many challenges. Users in these rural communities obtain a month of access to broadband for only R25. The Zenzeleni project has demonstrated how developing an innovative bottom-up community ownership model to address the digital divide where normal market forces have failed, is actually feasible. 
What we need, therefore, is policy innovation to enable more Zenzeleni's to prosper and thrive so that the digital ecosystem is realised in communities that live below the poverty line. This will create a far greater chance of actually defeating the problem of digital inequality that I referred to at the outset.

\section{Beyond access : towards effective use of ICT in micro and small business}

An industry growth value chain for small businesses within a supportive ICT policy environment is required. This value chain must be supported by Government incentives; subsidised Community ICT access; regional ICT Innovation Hubs; and angel investors. All of the latter will thrive in a policy environment that balances both the supply and demand problems in which there is no domination in the telecommunications market; in which fair competition exists; and where all pillars of Universal Access as described in the White Paper, are supported by the Digital Development Fund.

Closing the digital gender gap starts with the awareness and marketing of incentives and the available support. This in turn, will lead to social innovation and the birth of entrepreneurs, supported by government incentives. Those incentives can give rise to new start-ups that will ultimately deliver products to the market and thus become full participants in the national economy.

Finally, entrepreneurs must be capacitated to understand how to make their businesses grow in a digital society. Our goal must be to ensure a shared understanding of how to enable the adoption of ICTs and its integration into a business. There is no shortage of ICT applications that could support small enterprises. However, we are short on strategies to help entrepreneurs to overcome technophobia and to create sustainable business ventures through innovative application of ICT. Our research has shown consistently that it is not so much about the technology, but about the ability to understand how to use it wisely to promote an entrepreneurial mindset. 